\title{
Worldwide increase in incidence of Type I diabetes - the analysis of the data on published incidence trends
}

\section{P. Onkamo, S. Väänänen, M. Karvonen, J. Tuomilehto}

Diabetes and Genetic Epidemiology Unit, Department of Epidemiology and Health Promotion, National Public Health Institute, Helsinki, Finland

\section{Abstract}

Aims/hypothesis. Several reports on the incidence of Type I (insulin-dependent) diabetes mellitus have suggested that the incidence is increasing. The aim of this study was to find out whether the incidence is increasing globally or restricted to a selected populations only and to estimate the magnitude of the change in incidence.

Methods. During 1960 to 199637 studies in 27 countries were carried out. To fulfil the inclusion criteria the study periods ranged from 8-32 years. The temporal trend was fitted by linear regression, with the logarithm of the age-standardized incidence as the dependent variable and the calendar year as the independent variable. Then, the regression coefficient $(\times 100 \%)$ is approximately the average relative increase in incidence per year (as percentage).

Results. Results from the pooled data from all 37 populations showed that the overall increase in incidence was $3.0 \%$ per year $(95 \%$ CI 2.6; 3.3, $p=0.0001)$. The statistically significant increase was found in 24 of 37 populations including all high incidence ( $>14.6$ per 100000 a year) populations. The relative increase was, however, steeper in the populations with a lower incidence. The correlation between logarithm of the incidence and the increase in incidence was $r=-0.56, p=0.0004$.

Conclusion/interpretation. The incidence of Type I diabetes is increasing worldwide both in low and high incidence populations. By the year 2010 the incidence will be 50 per 100000 a year in Finland and also in many other populations it will exceed 30 per 100000 a year. [Diabetologia (1999) 42: 1395-1403]

Keywords Epidemiology, geographical variation, incidence, increase, modelling, prediction, trend, Type I diabetes.
The aetiology and natural history of Type I (insulindependent) diabetes mellitus are still not known but both genetics and environmental factors contribute to the development of the disease [1-3]. Although HLA genetics have a major role in the aetiology of Type I diabetes, other genes also contribute to the genetic effect, but the mode of inheritance of the disease is not clear [4]. The genetic effect contributes

Received: 3 May 1999 and in final revised form: 17 August 1999

Corresponding author: J. Tuomilehto, Diabetes and Genetic Epidemiology Unit, Department of Epidemiology and Health Promotion, National Public Health Institute, Mannerheimintie 166, FIN-00300 Helsinki, Finland
$70-75 \%$ of the susceptibility to Type I diabetes [5, $6]$. Environmental factors possibly initiate or trigger the process which leads to the destruction of the beta cells and the onset of diabetes $[3,7,8]$.

In the late $1970 \mathrm{~s}$ epidemiological reports of diabetic children for the first time showed a wide geographical variation in the incidence of Type I diabetes. During the 1960 s to the early 1980 s the data on incidence of Type I diabetes were available for a few populations only, mostly from regions with a high or intermediate risk for this disease. A large number of registries had been established since the mid 1980s worldwide. The lack of standardized data made it difficult to determine the true magnitude of the worldwide variation in incidence or time trends [9]. The Di- 
abetes Epidemiology Research International Group (DERI) started the collection of the aggregate data on incidence of Type I diabetes in the late 1970s and the early 1980s [10]. The efforts of the DERI group led to an increase in the number of registries on diabetic children and to the establishment of the World Health Organization Project of Childhood Diabetes (DIAbetes MONdiale) in 1990 [11]. The collaborative research project EURODIAB ACE was established also in the late 1980s [12] to gather information of Type I diabetes in Europe. The latest reviews on the incidence of Type I diabetes among populations have indicated that differences in the incidence are 60 -fold between the highest and the lowest rates [10, 12-14]. The highest incidence is found in Caucasoid populations, particularly in northern Europe, and the lowest rates are found in Asia and South America $[13,14]$.

Thus far only one trend analysis of the incidence of Type I diabetes comparing simultaneously several but yet a limited number of populations has been carried out by the DERI group [15]. The standardized procedures agreed upon for the incidence data collected around the world now permit a comparative assessment of temporal trends among several populations. We estimated the temporal trends in the incidence of Type I diabetes from incidence data collected through a systematic literature review. A statistical analysis of the data was done in order to find out whether the incidence is increasing globally. Another objective was to evaluate quantitatively the extent to which the change in incidence of Type I diabetes differs among populations.

\section{Materials and methods}

Literature search. The literature was searched using MEDLINE, direct examination of reference lists of the articles, hand searches of selected journals and published conference abstracts. By the closing date, 28th February 1999, more than 160 original publications reporting time series of the incidence of Type I diabetes were found.

Inclusion criteria. The publications were further evaluated with the strict inclusion criteria in order to choose appropriate studies for the quantitative analysis. The inclusion criteria were: 1) the study period was 8 years or more, 2) the incidence rates were presented for each year separately, 3) the number of cases per year was five or more, 4) in the papers in which the age standardization had been reported, the incidences had been estimated with age standardization according to the world population and, 5) Type I diabetes was diagnosed according to the WHO definition. Studies comparing incidence rates estimated with different methods during different periods were excluded. No requirement for a minimum case-ascertainment level of the data source was made as reliable case ascertainment estimation had usually not been done until the $1990 \mathrm{~s}$. The articles were evaluated by two independent reviewers according to the above-mentioned inclusion criteria.
Description of the data. Incidence data were obtained either from the tables or from the figures in the published articles. In approximately half of the original articles the annual incidence rates were presented in the tables and in another half in the figures only. The numbers derived from the figures were reconfirmed by the second reviewer. For Montreal (Canada), Allegheny County (USA), Scotland, Auckland (New Zealand), Prince Edward Island (Canada), Leicestershire (UK) and Wielkopolska (Poland) we used the original database of the DERI Study [15].

Altogether 37 studies from 27 countries met the inclusion criteria and were included in the analysis (Table 1 ). The registration of diabetic children was prospective in most of the studies. In 30 studies the age of children ranged from 0 to 14 years and in 7 studies from 0 to $15,16,17$ and 19 years. The time period of the studies ranged from 8 to 32 years. The average length of the study period was 14.9 years (median 14 years). The estimates of the degree of case-ascertainment were high, ranging from 85 to $100 \%$. The degree of ascertainment remained unspecified only in five studies. The studies included in the analysis were from the period 1960 to 1996.

Statistical methods. The incidence of Type I diabetes for our analysis was taken from the individual studies as it was reported in these publications. The incidence for the data obtained from the DERI Study [15] was calculated per 100000 people a year. Age standardization of the rates was done using 5-year intervals with the proportions 33/100, 33/100 and 34/100 (for the age groups $0-4$ years, 5-9 years, and 10-14 years respectively) as the standard according to the approach by the DERI Study Group [16], which is the same as the world population standard.

The temporal trend for each population was fitted by a simple linear regression under the assumption of normally distributed errors, with the age-standardized incidence as dependent variable expressed on a logarithmic scale and the calendar year as independent variable: $\ln \lambda_{\mathrm{i}}(t)=\alpha_{\mathrm{i}}+\beta_{\mathrm{i}} t$, where $\lambda_{\mathrm{i}}(t)$ denote the age-standardized incidence predicted at year $t$ for population $i$; the intercept $a_{i}$ is different for each population, and $\beta_{\iota}$ is the population specific regression coefficient (the trend), respectively. In such a multiplicative model the regression coefficient $(\times 100 \%)$ is a percentage, approximately being the average relative increase in incidence per year. The multiplicative regression model was used because it fitted the data well. It is commonly used in estimating time trends in incidence and allows a simple interpretation of the regression coefficient.

The overall estimate of the relative annual increase was obtained by using a pooled, centralized data set: to start, for each population the logarithms of the age-standardized incidence rates and the time points were centralized to make the different lengths of the studies and incidence levels more comparable. Then, using the method of least squares, a straight line constrained to cross the origin of the centralized coordinate system was fitted to the pooled data set. The regression coefficient has the same interpretation as in the population-wise analysis. The analysis was subsequently repeated as weighted regression, where the residual sum of squares was weighted with the number of cases in individual studies, to give more weight for observations with a higher number of cases.

The association between the level of incidence and increase in incidence was assessed by calculating the correlation coefficient between the logarithms of incidences in 1983 predicted by the model and the incidence increases estimated by the multiplicative model. The year 1983 was chosen because almost all studies covered it. 
Table 1. The studies included in the analysis

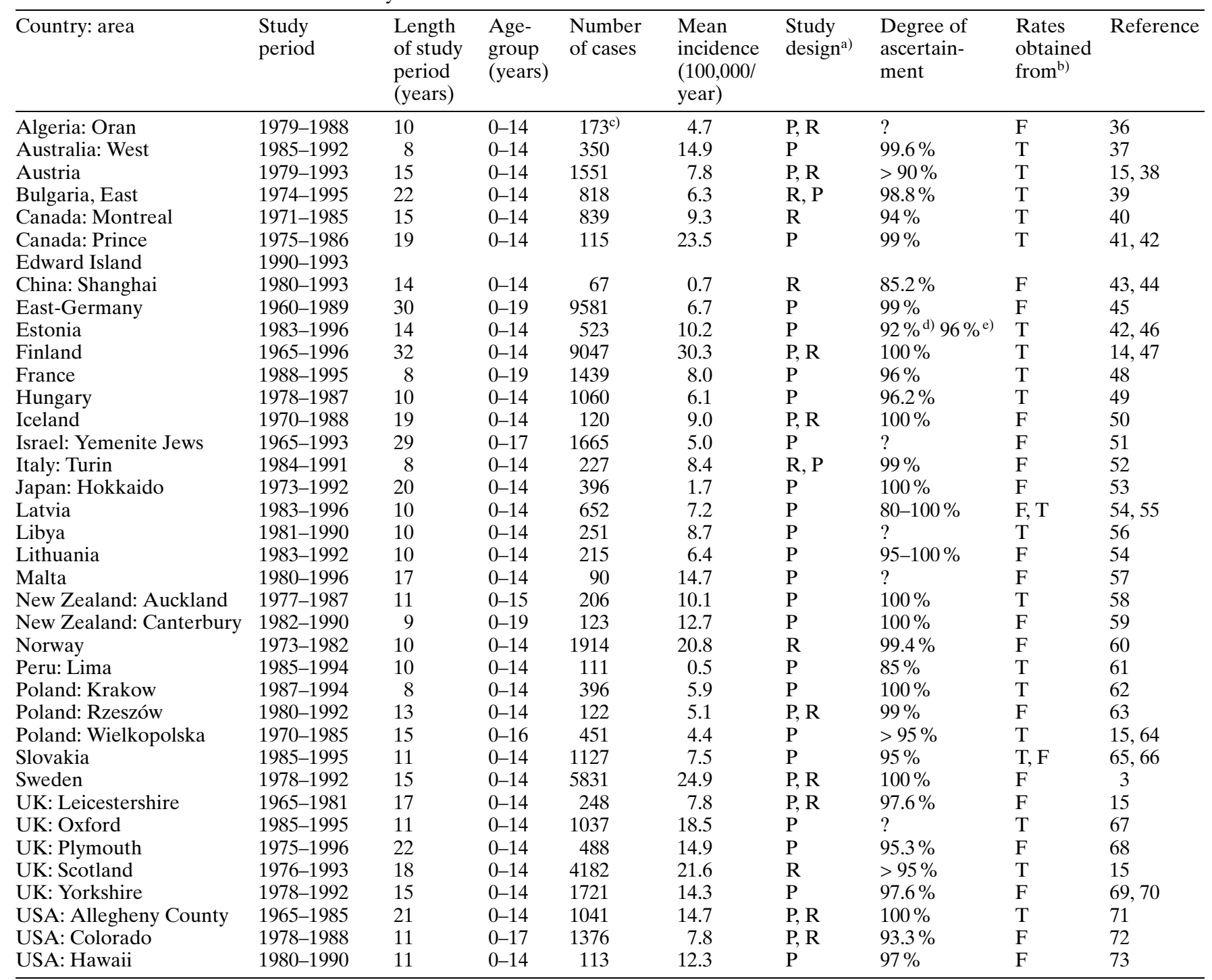

a) $\mathrm{P}=$ prospective, $\mathrm{R}=$ retrospective ${ }^{\mathrm{b})} \mathrm{F}=$ figure, $\mathrm{T}=$ table ${ }^{\mathrm{c})}$ families ${ }^{\mathrm{d}}$ non Estonian ${ }^{\mathrm{e}}$ Estonian

Predictions until the year 2010 have been made with both multiplicative and additive regression models, meaning that the curve produced by fitting the model to the data is simply extrapolated to the year 2010. In essence, the multiplicative model fits an exponential curve to the incidence, whereas the additive model fits a straight line. The additive regression model is used here to point out the differences between predictions when using alternative models.

\section{Results}

Incidence. The mean incidence of Type I diabetes among the study populations varied from 0.5 to 30.3 per 100000 a year during the observation period (Table 1). The mean incidences were divided into quartiles: low incidence, less than 6.4 per 100000 a year (the lowest $25 \%$ of the mean incidences), intermediate $6.4-14.6$ per 100000 a year $(50 \%$ of the mean in- cidences, thus the two intermediate groups combined), and high, more than 14.6 per 100000 a year (highest $25 \%$ of the mean incidences).

Increase in the incidence of Type I diabetes. The relative change (\% per year) in incidence among individual populations ranged from $-0.2 \%$ in Colorado (USA) to $9.5 \%$ in Leicestershire (UK) (Table 2). A statistically significant increase in incidence was found in $65 \%(24 / 37)$ of the populations. An upward tendency in incidence not reaching statistical significance was observed in another 12 populations. Only in one population, Colorado (USA), the trend was slightly, but not significantly, negative $(-0.2 \%$ per year $)$ and the upper limit of the $95 \%$ confidence interval show that an increase of $2.2 \%$ per year was possible.

The global trend and the annual increase in the incidence of Type I diabetes were estimated from the 
Table 2. Relative increase in incidence of Type I diabetes in children aged 14 years or less in 37 populations. The populations are arranged in descending order according to the rela- tive increase per year. The $95 \%$ confidence interval is given in the parentheses. $P$ value stands for the two-sided test for a nonzero regression coefficient

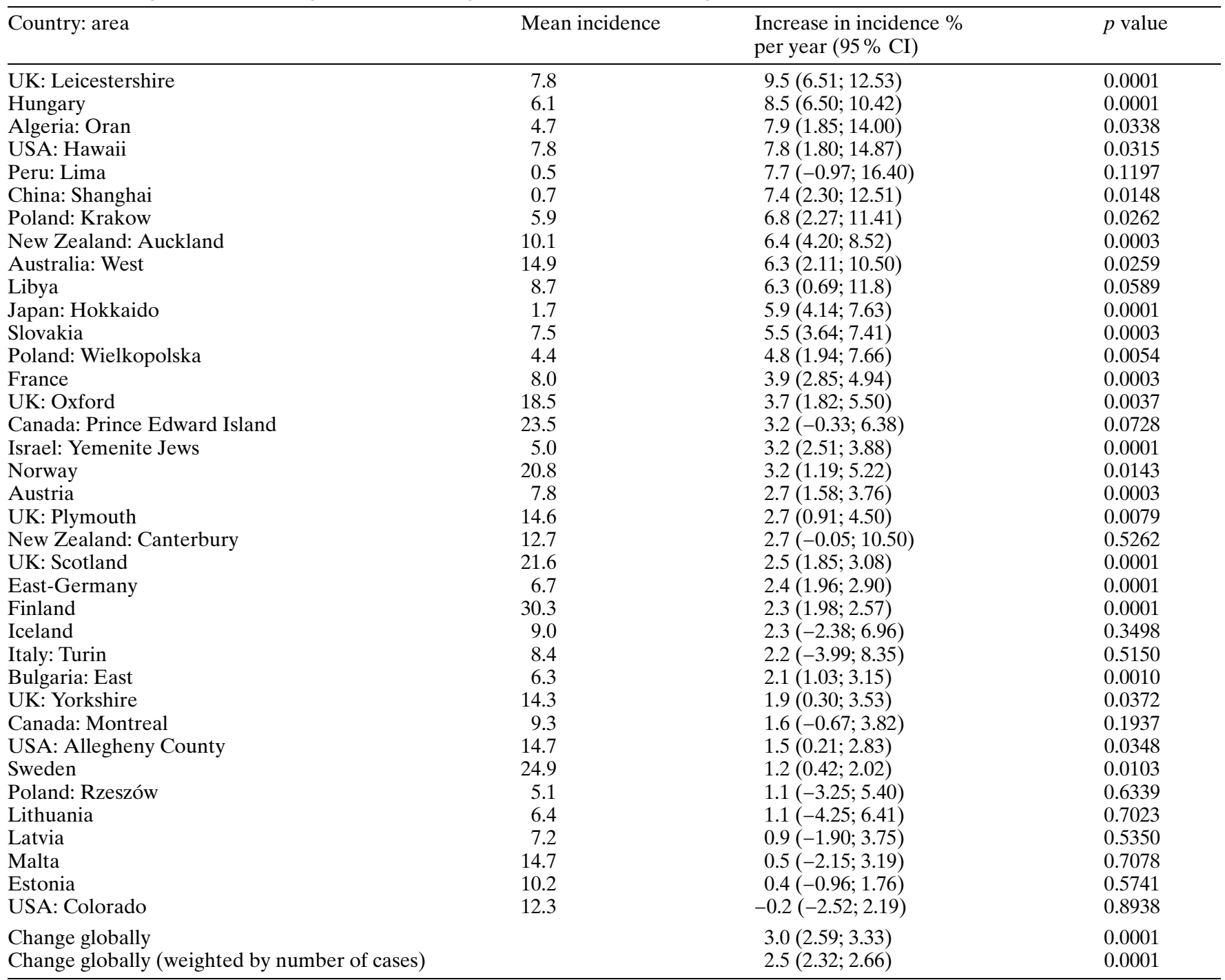

age-standardized incidence rates using the log-linear regression (Table 2). The $p$ value of less than 0.05 for the two-sided test for a non-zero regression coefficient was regarded as evidence for the trend. The global annual increase was $3.0 \%$ (95\% CI 2.59; 3.33, $p=0.0001$ ) during 1960 to 1996 , showing a highly significant increasing trend. When the annual incidence rates were weighted with the number of cases in each individual study, the increase in incidence was $2.5 \%(95 \%$ CI $2.32 ; 2.66 ; p=0.0001)$. The estimated population-wise regression lines illustrate well the increasing trends (Fig. 1, 2).

Comparison of increase rates. The relation between the increase in incidence of Type I diabetes and the average level of incidence expressed as the incidence in 1983 estimated from the regression model is shown in Figure 3. There was a significant inverse association between the increase and the logarithm of the level of incidence $(r=-0.56, p=0.0004)$. The association indicates that the relative increase was more pronounced in the populations with a low incidence. Nevertheless, in the five populations with the highest incidence the increase was also statistically significant, varying from 1.2 to $3.2 \%$ per year.

The incidence level of Type I diabetes and its increase seemed to be similar in some geographically adjacent populations. For example in the northern European countries; Finland, Sweden and Norway where the incidence of Type I diabetes has been high for a long time, the increase was 1 to $3 \%$ per year. Adjacent countries around the Baltic Sea, Estonia, Latvia, Lithuania and Poland with an intermediate or low incidence (4-10 per 100000 a year) showed 
Incidence per 100000 a year

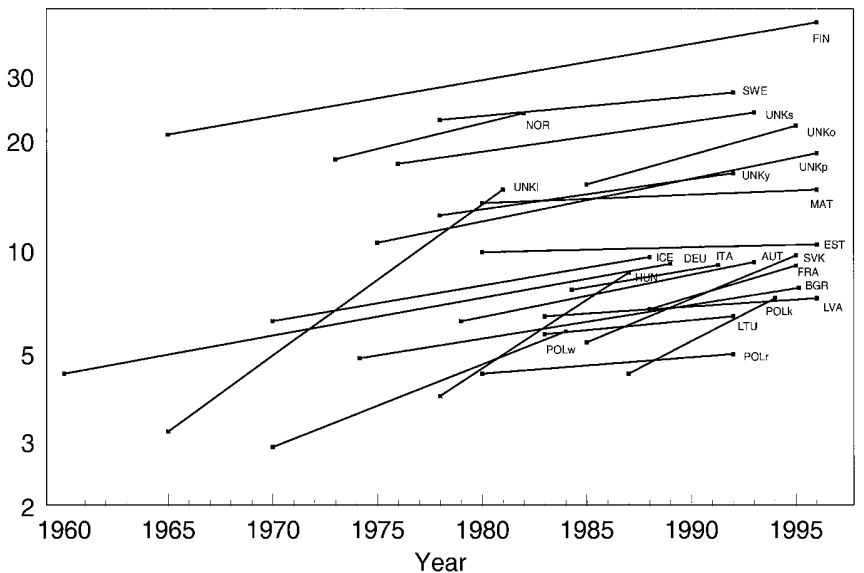

Fig. 1. Trends in incidence of Type I diabetes in European populations. AUT: Austria; BGR: Bulgaria; DEU: East-Germany; EST: Estonia; FIN: Finland; FRA: France; HUN: Hungary; ICE: Iceland; ITA: Italy (Turin); LVA: Latvia; LTU: Lithuania; MAT: Malta; NOR: Norway; POLk: Poland (Krakow); POLr: Poland (Rzeszów); POLw: Poland (Wielkopolska); SVK: Slovakia; SWE: Sweden; UNKl (UK, Leicestershire); UNKo (Oxford); UNKp (Plymouth); UNKs (Scotland); UNKy (Yorkshire). The model fitted to the incidence data was a multiplicative regression model with logarithm of the age standardized incidence as dependent variable, thus the scale of the incidence is logarithmic when straight lines were used in drawing the regression lines

an upward course but not a statistically significant trend in incidence. The increase in incidence in eastern Europe varied from $2.1 \%$ per year in East Bulgaria to $8.5 \%$ per year in Hungary. In the United Kingdom the mean incidence ranged from 14.3 to 21.6 and the increase in incidence ranged between 1.9 and $3.7 \%$ except for Leicestershire where the mean incidence was 7.8 with an increase of $9.5 \%$. The data for Leicestershire, however, were considerably older (from 1965 to 1981) than from other UK study populations.

Predictions until the year 2010. Since no effective prevention has thus far been invented or is foreseen in the near future, we used the observed trends to predict the incidence of Type I diabetes at least until the year 2010 (Table 3). For the prediction we applied both linear and exponential models, since the model of the increase in incidence is not known. The exponential predictions were only calculated for populations with a study period of at least 14 years. In general, the linear model produces more conservative predictions than the exponential model, however, in those populations where an increase had started during the very last years of the observation period, the exponential model gave more conservative predictions than the linear.

The predictions based on the linear model show that Finland will still have the highest incidence in
Incidence per 100000 a year

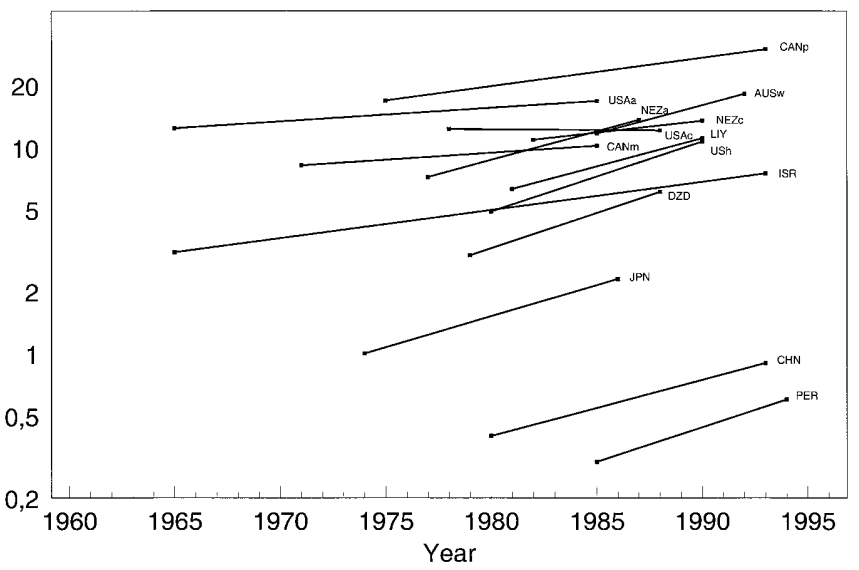

Fig. 2. Trends in the incidence of Type I diabetes mellitus in Non-European populations. DZD: Algeria (Oran); AUSw: Australia (West); CANm: Canada (Montreal); CANp: Canada (Prince Edward Island); CHN: China (Shanghai); ISR: Israel (Yemenite Jews); JPN: Japan (Hokkaido); LIY: Libya; NEZa: New Zealand (Auckland); NEZc: New Zealand (Canterbury); PER: Peru (Lima); USAa: USA (Allegheny County); USAc: USA (Colorado); USAh: USA (Hawaii)

the world (50 per 100000 a year) in the year 2010, followed by Norway, Prince Edward Island (Canada), western Australia, Scotland (UK), Oxford (UK), and Sweden. Despite the large relative increases in the incidence observed in China and Peru, the absolute incidence rates in these countries would still remain low, less than 2 per 100000 a year. Based on these predictions, in Japan the incidence will be lower than 5 per 100000 a year and in Poland, Latvia and Lithuania the incidence will be under 10 per 100000 a year.

\section{Discussion}

There are also other populations in which an increase in the incidence of Type I diabetes has been recently reported such as Croatia, Denmark, Kuwait, the Netherlands, Russia and Switzerland [17-23]. These studies, however, did not meet the inclusion criteria of this study and were not included in our analysis. To find out whether the rising incidence is really a global phenomenon, we carried out an analysis of incidence trends among 37 populations worldwide for which the data had been collected for 8 years or more. The incidence of Type I diabetes is globally increasing by $3.0 \%$ per year (or by $2.5 \%$, when the incidences were weighted by the number of diabetic children included in the individual studies). Confidence intervals for these estimates were fairly narrow indicating that these estimates are reliable. According to this estimate, the incidence of Type I diabetes will be $40 \%$ higher in 2010 than in 1998 . This is a realistic, although a rather frightening, scenario. 


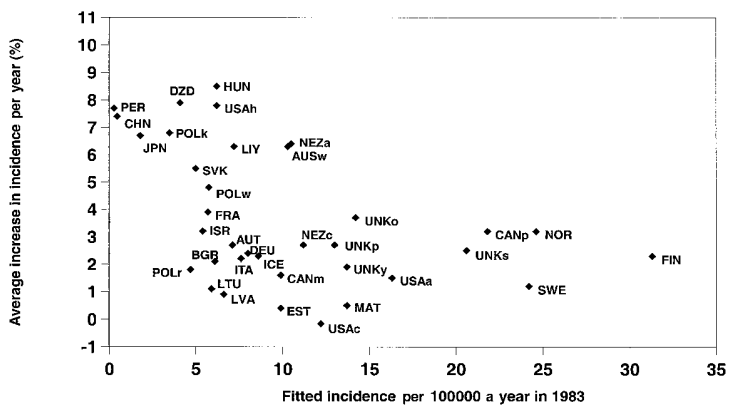

Fig. 3. Association between the increase in incidence and the level of incidence of Type I diabetes. The correlation coefficient between the log-transformed level of incidence predicted for 1983 and the increase in incidence was $-0.56(p=0.0004)$ for all populations. The increase in incidence was estimated from multiplicative regression models. For each population the level of incidence was calculated as the model-predicted (fitted) incidence in 1983 according to the multiplicative regression model. Leicestershire, UK, has been excluded. DZD: Algeria (Oran); AUSw: Australia (West); AUT: Austria; BGR: Bulgaria; CANm: Canada (Montreal); CANp: Canada (Prince Edward Island); CHN: China (Shanghai); DEU: EastGermany; EST: Estonia; FIN: Finland; FRA: France; HUN: Hungary; ICE: Iceland; ISR: Israel (Yemenite Jews); ITA: Italy (Turin); JPN: Japan (Hokkaido); LVA: Latvia; LIY: Libya; LTU: Lithuania; MAT: Malta; NEZa: New Zealand (Auckland); NEZc: New Zealand (Canterbury); NOR: Norway; PER: Peru (Lima); POLk: Poland (Krakow); POLr: Poland (Rzeszów); POLw: Poland (Wielkopolska); SVK: Slovakia; SWE: Sweden; UNKo: UK (Oxford); UNKp: UK (Plymouth); UNKs: UK (Scotland); UNKy: UK (Yorkshire); USAa: USA (Allegheny County); USAh: USA (Hawaii); USAc: USA (Colorado)

The global variation in the incidence of Type I diabetes is prominent $[10,13,14]$. It reflects the distribution of ethnic diversity showing the importance of the differential genetic susceptibility among populations. The incidence is higher among Caucasoid populations than among Mongoloids and Blacks. Within ethnic groups, however, there are geographical differences in incidence depending on the admixture between racial groups and possible environmental exposures [13]. Although most of the populations included in this analysis were Caucasoid, statistically significant increases in incidence were also found among the Asian populations in China and Japan, Mestizos in Peru and also among the Polynesians in Hawaii. In this literature review it was not possible to account for ethnic differences within populations because the authors of the original papers had usually not given detailed information on incidence in different ethnic groups. Where the ethnic groups had been analyzed separately, however, an increase in the incidence had been observed in all groups, but the rate of increase could vary from one ethnic group to another. Overall, the increase in the incidence of Type I diabetes does not seem to be restricted to any particular ethnic group.
Table 3. Predicted incidence (100000 per year) of Type I diabetes in children aged 14 years or less by the year 2010 according to both the multiplicative and additive regression model. The populations are arranged in descending order according to the predicted incidence in 2010 based on the additive model. Only the populations with a study period covering 14 years or more were included in predictions with the multiplicative model

\begin{tabular}{|c|c|c|}
\hline \multirow[t]{2}{*}{ Country: area } & \multicolumn{2}{|c|}{$\begin{array}{l}\text { Predicted incidence per } \\
100000 / \text { year in } 2010\end{array}$} \\
\hline & $\begin{array}{l}\text { Additive } \\
\text { regression } \\
\text { model }\end{array}$ & $\begin{array}{l}\text { Multiplicative } \\
\text { regression } \\
\text { model }\end{array}$ \\
\hline Finland & 50.2 & 57.9 \\
\hline Norway & 41.8 & \\
\hline Canada: Prince Edward Island & 39.2 & 51.4 \\
\hline Australia: West & 36.7 & \\
\hline UK: Scotland & 34.9 & 40.0 \\
\hline UK: Oxford & 33.0 & \\
\hline Sweden & 32.2 & 33.7 \\
\hline New Zealand: Auckland & 27.7 & \\
\hline New Zealand: Canterbury & 25.0 & \\
\hline UK: Plymouth & 23.4 & 27.0 \\
\hline USA: Allegheny County & 22.5 & 24.5 \\
\hline USA: Hawaii & 21.4 & \\
\hline UK: Yorkshire & 21.0 & 23.0 \\
\hline Hungary & 20.1 & \\
\hline Libya & 19.0 & \\
\hline Malta & 16.8 & 15.8 \\
\hline Iceland & 16.1 & 16.0 \\
\hline Slovakia & 16.0 & \\
\hline Algeria: Oran & 15.2 & \\
\hline Canada: Montreal & 14.8 & 15.0 \\
\hline France & 13.7 & \\
\hline Poland: Krakow & 13.0 & \\
\hline Italy: Turin & 12.8 & \\
\hline Austria & 12.8 & 14.6 \\
\hline East Germany & 12.0 & 15.4 \\
\hline USA: Colorado & 12.0 & \\
\hline Poland: Wielkopolska & 11.8 & 20.2 \\
\hline Estonia & 10.9 & 11.0 \\
\hline Bulgaria: East & 10.3 & 10.7 \\
\hline Israel: Yemenite Jews & 10.1 & 12.9 \\
\hline Latvia & 8.9 & \\
\hline Lithuania & 7.5 & \\
\hline Poland: Rzeszów & 6.7 & \\
\hline Japan: Hokkaido & 4.1 & 7.9 \\
\hline China: Shanghai & 1.7 & 3.3 \\
\hline Peru: Lima & 1.3 & \\
\hline
\end{tabular}

In most countries with a low incidence the standardized incidence data have been collected during a relatively short period, which may in some cases explain the large relative change in incidence. The incidence of Type I diabetes possibly has been underestimated in earlier studies because of incomplete caseascertainment and death from undiagnosed diabetes. Among those populations where the study period was 18 years or more the increase in incidence was usually low (from 1.5 to $3.2 \%$ per year except Japan, Hokkaido, $5.9 \%$ ). Therefore, results from several individual populations showing large increases should be interpreted cautiously when the number of cases 
is small and the study period short. The analysis of the pooled data was repeated excluding populations for which the case ascertainment level was not reported (Algeria, Israel, Libya, Malta and Oxford, UK). The results were essentially the same as in the analysis using all data: $2.95 \%$ per year vs $2.96 \%$ per year, respectively, and for the weighted regression, $2.40 \%$ vs $2.49 \%$, respectively.

There is presently no way to know whether the observed trend in incidence might reflect a change in the age at onset of diabetes instead of a true rise in prevalence. The increase in incidence in 0-14-yearolds might just be a transition of the age at onset from the age group 15 years or older. Data on incidence trends in older age groups exist from just a few populations; thus, reliable information a possible decrease in incidence in young adults is not available. Our main result is that the incidence is globally increasing in the age group of $0-14$-year-olds.

The genetic factors have been shown to be important in the susceptibility to Type I diabetes [5, 6]. Although it is possible that the part of the population genetically predisposed for Type I diabetes is increasing, this increase may have been modest during the last decades and not alone a sufficient cause for the observed increase in incidence. The changes in the genetic code of the human populations are usually slow. In this analysis even the longest study period covered only 30 years, which is approximately the time span of one generation. It is very unlikely that a three to tenfold increase in the proportion of subjects with genetic susceptibility to Type I diabetes has taken place in any population during such a short time. Instead, the penetrance of the susceptibility genes might be changing. The penetrance is likely to be determined by an interaction between several susceptibility genes and unknown environmental factors [4, 24].

During the recent years much attention has been paid to the identification and possible control of environmental factors which possibly initiate or trigger the process leading to Type I diabetes. Although some studies suggest associations between environmental factors such as diet and viral infections with the risk of Type I diabetes [25-35], their causative role has not been shown. It is also difficult to show that any of these environmental factors has changed in such a way that a continuous global increase in the incidence of Type I diabetes would be easily explained.

The incidence of Type I diabetes is increasing worldwide. Thus far no population has been identified in which the incidence has significantly decreased. The population-based WHO DIAMOND Project and the EURODIAB study started at the beginning of the $1990 \mathrm{~s}$ but have not yet reported results from the long-term progress in the incidence of Type I diabetes. It seems obvious that in both of these studies the 10-year monitoring period planned thus far is too short to produce reliable trend estimations and predictions for the change of the incidence of Type I diabetes, especially in countries where incidence is low. There is a need to continue with the community-based registries on Type I diabetes worldwide. Efforts are also needed to identify effective primary prevention measures for Type I diabetes to stop the global increase in the incidence of this disease.

Acknowledgements. We thank the Diabetes Epidemiology Research International (DERI) Group for the data for several countries used in this study.

\section{References}

1. Cudworth AG, Wolf E, Gorsuch AN, Festenstein H (1979) A new look at HLA genetics with particular reference to type-1 diabetes. Lancet 2: 389-391

2. Tuomilehto-Wolf E, Tuomilehto J (1991) HLA antigens in insulin-dependent diabetes mellitus. Ann Med 23: 481488

3. Dahlquist G, Mustonen L (1994) Childhood onset diabetes - time trends and climatological factors. Int J Epidemiol 23: 1234-1241

4. Todd JA (1997) Genetics of type 1 diabetes. Pathol Biol (Paris) 45: 219-227

5. Kaprio J, Tuomilehto J, Koskenvuo M et al. (1992) Concordance for type 1 (insulin-dependent) and type 2 (non-insulin-dependent) diabetes mellitus in a population-based cohort of twins in Finland. Diabetologia 35: 1060-1067

6. Kyvik KO, Green A, Beck-Nielsen H (1995) Concordance rates of insulin dependent diabetes mellitus: a population based study of young Danish twins. BMJ 311: 913-917

7. Blom L, Nyström L, Dahlquist GG (1991) The Swedish childhood diabetes study: vaccinations and infections as risk determinants for diabetes in childhood. Diabetologia 34: 176-181

8. Virtanen SM, Räsänen L, Aro A et al. (1992) Feeding in infancy and the risk of type 1 diabetes mellitus in Finnish children. Diabet Med 9: 815-819

9. LaPorte RE, Tajima N, Åkerblom HK et al. (1985) Geographic differences in the risk of insulin-dependent diabetes mellitus: the importance of registries. Diabetes Care 8[Suppl 1]:S101-S107

10. Rewers M, LaPorte RE, King H, Tuomilehto J (1988) Trends in the prevalence and incidence of diabetes: insulin-dependent diabetes mellitus in childhood. World Health Stat Q 41: 179-189

11. WHO DIAMOND Project Group on Epidemics (1992) Childhood diabetes, epidemics, and epidemiology: an approach for controlling diabetes. Am J Epidemiol 135: 803-816

12. Green A, Gale EA, Patterson CC for the EURODIAB ACE study (1992) Incidence of childhood-onset insulin-dependent diabetes mellitus: the EURODIAB ACE study. Lancet 339: 905-909

13. Karvonen M, Tuomilehto J, Libman I, LaPorte R for the World Health Organization DIAMOND Project Group (1993) A review of the recent epidemiological data on the worldwide incidence of type 1 (insulin-dependent) diabetes mellitus. Diabetologia 36: 883-892

14. Karvonen M, Pitkäniemi M, Pitkäniemi J, Kohtamäki K, Tajima N, Tuomilehto J for the World Health Organization 
DIAMOND Project Group (1997) Sex difference in the incidence of insulin-dependent diabetes mellitus: an analysis of the recent epidemiological data. Diabetes Metab Rev 13: 275-291

15. Diabetes Epidemiology Research International Group (1990) Secular trends in incidence of childhood IDDM in 10 countries. Diabetes 39: 858-864

16. Diabetes Epidemiology Research International Group (1988) Geographic patterns of childhood insulin-dependent diabetes mellitus. Diabetes 37: 1113-1119

17. Schoenle EJ, Molinari L, Bagot M, Semadeni S, Wiesendanger M (1994) Epidemiology of IDDM in Switzerland. Increasing incidence rate and rural-urban differences in Swiss men born 1948-1972. Diabetes Care 17: 955-960

18. Ruwaard D, Gijsen R, Bartelds IM, Hirasing RA, Verkleij $H$, Kromhaut D (1996) Is the incidence of diabetes increasing in all age-groups in The Netherlands? Results of the second study in the Dutch Sentinel Practice Network. Diabetes Care 19: 214-218

19. Bingley PJ, Gale EA (1989) Rising incidence of IDDM in Europe. Diabetes Care 12: 289-295

20. Green A, Andersen PK, Svendsen AJ, Mortensen K (1992) Increasing incidence of early onset type 1 (insulin-dependent) diabetes mellitus: a study of Danish male birth cohorts. Diabetologia 35: 178-182

21. Jaksic J, Matic I, Stojnic E, Juros A, Pelajic A (1996) Incidence of insulin dependent diabetes mellitus in children aged 0-19 in the Sibenic area. Diabetol Croat 29-33

22. Choubnikova J, Shubnikof E, Kalashnikova L (1996) The increase of type 1 diabetes incidence among children in Novosibirsk city. 32nd Annual Meeting of the European Association for the Study of Diabetes, Vienna (Abstract)

23. Shaltout AA, Qeabazard MA, Abdella et al. (1995) High incidence of childhood-onset IDDM in Kuwait. Diabetes Care 18: 923-927

24. Cordell HJ, Todd JA (1995) Multifactorial inheritance in type 1 diabetes. Trends Genet 11: 499-504

25. Borch-Johnsen K, Joner G, Mandrup-Poulsen $\mathrm{T}$ et al. (1984) Relation between breast-feeding and incidence rates of insulin-dependent diabetes mellitus. A hypothesis. Lancet 2: 1083-1086

26. Kostraba JN, Cruickshanks KJ, Lawler-Heavner J et al. (1993) Early exposure to cow's milk and solid foods in infancy, genetic predisposition, and risk of IDDM. Diabetes 42: 288-295

27. Elliott RB, Martin JM (1984) Dietary protein: a trigger of insulin-dependent diabetes in the BB rat? Diabetologia 26: 297-299

28. Helgason T, Jonasson MR (1981) Evidence for a food additive as a cause of ketosis-prone diabetes. Lancet 2: 716-720

29. Dahlquist GG, Blom LG, Persson LA, Sandström AI, Wall SG (1990) Dietary factors and the risk of developing insulin dependent diabetes in childhood. BMJ 300: 1302-1306

30. Virtanen SM, Jaakkola L, Räsänen L et al. (1994) Nitrate and nitrite intake and the risk for type 1 diabetes in Finnish children. Diabet Med 11: 656-662

31. Rayfield EJ, Seto Y (1978) Viruses and the pathogenesis of diabetes mellitus. Diabetes 27: 1126-1140

32. Gamble DR (1976) A possible virus etiology for juvenile diabetes. In: Creutzfeld W, Köbberlin J, Neel V (eds) The genetics of diabetes mellitus. Springer, Berlin Heidelberg New York, pp 95-105

33. Hyöty H, Leinikki P, Reunanen A et al. (1988) Mumps infections in the etiology of type 1 (insulin-dependent) diabetes. Diabetes Res 9: 111-116

34. Hyöty H, Hiltunen M, Knip M et al. (1995) A prospective study of the role of coxsackie $\mathrm{B}$ and other enterovirus in- fections in the pathogenesis of IDDM. Diabetes 44: 652-657

35. Hiltunen M, Hyöty H, Karjalainen J et al. (1995) Serological evaluation of the role of cytomegalovirus in the pathogenesis of IDDM: a prospective study. Diabetologia 38: 705-710

36. Bessaoud K, Boudraa G, Deschamps I, Hors J, Benbouabdallah M, Touhami M (1990) Epidemiologie du diabète insulinodépendant juvéline en Algérie (Wilaya D’Oran). Rev Epidemiol Sante Publique 38: 91-99

37. Kelly HA, Russell MT, Jones TW, Byrne GC (1994) Dramatic increase in incidence of insulin dependent diabetes mellitus in Western Australia. Med J Aust 161: 426-429

38. Schober E, Schneider E, Waldhör T, Tuomilehto J and Austrian Diabetes Incidence Study Group (1995) Increasing incidence of IDDM in Austrian children. A nationwide study 1979-1993. Diabetes Care 18: 1280-1283

39. Tzaneva V, Iotova V, Bruining GJ (1998) Increase in IDDM incidence in Bulgarian children (1974-1995). J Pediatr Endocrinol Metab 11: 725-732

40. Siemiatycki J, Colle E, Campbell S, Dewar R, Aubert D, Belmonte MM (1988) Incidence of IDDM in Montreal by ethnic group and by social class and comparisons with ethnic groups living elsewhere. Diabetes 37: 1096-1102

41. Tan MH, Wornell MC, Beck AW (1981) Epidemiology of diabetes mellitus in Prince Edward Island. Diabetes Care 4: 519-524

42. Väänänen S, Kohtamäki K, Karvonen M, Tuomilehto J for the Diamond Research Group (1997) Incidence of IDDM Worldwide Preliminary Analysis of the WHO DIAMOND Incidence Data. International Diabetes Epidemiology Group Symposium. Savonlinna, Finland (Abstract)

43. Fu H, Shen SX, Chen ZW et al. (1994) Shanghai, China, has the lowest confirmed incidence of childhood diabetes in the world. Diabetes Care 17: 1206-1208

44. Shen SX, Wang HB, Chen ZW et al. (1996) The incidence of insulin-dependent diabetes mellitus in urban districts of Shanghai (1989-1993). J Pediatr Endocrinol Metab 9: 469-473

45. Michaelis D, Jutzi E, Vogt L (1993) Epidemiology of insulin-treated diabetes mellitus in the East-German population: differences in long-term trends between incidence and prevalence rates. Diabetes Metab 19: 110-115

46. Podar T, LaPorte RE (1993) Incidence of childhood diabetes did not increase in Estonia during 1980-89. Diabetes Metab 19: 361-363

47. Tuomilehto J, Virtala E, Karvonen M et al. (1995) Increase in incidence of insulin-dependent diabetes mellitus among children in Finland. Int J Epidemiol 24: 984-992

48. Lévy-Marchal C, and Groupe du Registre d'incidence du Diabète Insulino-Dépendant de l'Enfant (1998) Évolution de l'incidence du diabète insulino-dépendant de l'enfant en France. Rev Epidemiol Sante Publique 46: 157-163

49. Soltész G, Madácsy L, Békefi D, Dankó I, the Hungarian Childhood Diabetes Epidemiology Group (1990) Rising incidence of Type 1 diabetes in Hungarian children (1978-1987). Diabet Med 7: 111-114

50. Helgason T, Danielsen R, Thorsson AV (1992) Incidence and prevalence of type 1 (insulin-dependent) diabetes mellitus in Icelandic children 1970-1989. Diabetologia 35: 880-883

51. Shamis I, Gordon O, Albag Y, Goldsand G, Laron Z (1997) Ethnic differences in the incidence of childhood IDDM in Israel (1965-1993) Marked increase since 1985, especially in Yemenite Jews. Diabetes Care 20: 504-508

52. Bruno G, Merletti F, De Salvia A, Lezo A, Arcari R, Pagano G, Piedmont Study Group for Diabetes Epidemiolo- 
gy (1997) Comparison of incidence of insulin-dependent diabetes mellitus in children and young adults in the province of Turin, Italy, 1984-91. Diabet Med 14: 964-969

53. Matsuura N, Fukuda K, Okuno A et al. (1998) Descriptive epidemiology of IDDM in Hokkaido, Japan: the Childhood IDDM Hokkaido Registry. Diabetes Care 21: 1632-1636

54. Padaiga Z, Tuomilehto J, Karvonen M et al. (1997) Incidence trends in childhood onset IDDM in four countries around the Baltic sea during 1983-1992. Diabetologia 40: 187-192

55. Brigis G, Robeza I (1997) Childhood onset IDDM incidence rates in Latvia. Outbreak in 1995, comparisons by ethnicity International Diabetes Epidemiology Group Symposium. Savonlinna, Finland (Abstract)

56. Kadiki OA, Moawad SE (1993) Incidence and prevalence of type 1 diabetes in children and adolescents in Benghazi, Libya. Diabet Med 10: 866-869

57. Schranz AG, Prikatsky V (1989) Type 1 diabetes in the Maltese Islands. Diabet Med 6: 228-231

58. Elliott RB, Pilcher CC (1985) Childhood diabetes in the Auckland area. N Z Med J 98: 922-923

59. Scott RS, Brown LJ, Darlow BA, Frobes LV, Moore MP (1992) Temporal variation in incidence of IDDM in Canterbury, New Zealand. Diabetes Care 15: 895-899

60. Joner G, Søvik O (1989) Increasing incidence of diabetes mellitus in Norwegian children 0-14 years of age 1973-1982. Diabetologia 32: 79-83

61. Seclén S, Rojas MI, Nuñez H, Valdivia H, Millones B, Diabetes Epidemiology Research Peruvian Group (DERPG) (1997) Type 1 (insulin-dependent) diabetes in Mestizo children of Lima, Peru. Report on a ten years (1985-94) incidence. International Diabetes Epidemiology Group Symposium. Savonlinna, Finland. (Abstract)

62. Szybìnski Z, Czyzyk A, Wasik R, Dziatkowiak H, Ciechanowska M, Symonides-Lawecka A, Szurkowska DP (1997) Epidemiology of IDDM in Poland - a 10 year perspective International Diabetes Epidemiology Group Symposium. Savonlinna, Finland (Abstract)

63. Grzywa MA, Sobel AK (1995) Incidence of IDDM in the province of Rzeszów, Poland, 0- to 29-year-old age-group, 1980-1992. Diabetes Care 18: 542-544
64. Rewers M, Stone RA, LaPorte RE et al. (1989) Poisson regression modeling of temporal variation in incidence of childhood insulin-dependent diabetes mellitus in Allegheny County, Pennsylvania, Wielkopolska, Poland, 19701985. Am J Epidemiol 129: 569-581

65. Michalková DM, Cernay J, Dankovà A, Rusnák M, Fandákova K, Slovak Childhood Diabetes Epidemiology Study Group (1995) Incidence and prevalence of childhood diabetes in Slovakia (1985-1992). Diabetes Care 18: 315-320

66. Michalkova D, Barak L, Dankova A, Pastor K, Mikulecky M, Cernay J, Slovak Pediatric Epidemiology Group (1997) The incidence and prevalence of type 1 diabetes mellitus in Slovak children from 1985 to 1995. International Diabetes Epidemiology Group Symposium. Savonlinna, Finland (Abstract)

67. Gardner SG, Bingley PJ, Sawtell PA, Weeks S, Gale EA, the Bart's-Oxford Study Group (1997) Rising incidence of insulin dependent diabetes in children aged under 5 years in the Oxford region: time trend analysis. BMJ 315: 713-717

68. Zhao HX, Stenhouse E, Soper C et al. (1999) Incidence of childhood onset Type I diabetes mellitus in Devon and Cornwall, England, 1975-1996. Diabetic Med 16: (in press)

69. Staines A, Bodansky HJ, Lilley HE, Stephenson C, McNally RJ, Cartwright RA (1993) The epidemiology of diabetes mellitus in the United Kingdom: The Yorkshire Regional Childhood Diabetes Register. Diabetologia 36: 1282-1287

70. McKinney PA, Law G, Staines AS, Bodansky HJ (1995) Incidence of diabetes in children. BMJ 310: 1672

71. LaPorte RE, Fishbein HA, Drash AL et al. (1981) The Pittsburgh insulin-dependent diabetes mellitus (IDDM) registry: the incidence of insulin-dependent diabetes mellitus in Allegheny County, Pennsylvania (1965-1976). Diabetes 30: 279-284

72. Kostraba JN, Gay EC, Cai Yet al. (1992) Incidence of insulin-dependent diabetes mellitus in Colorado. Epidemiology 3: 232-238

73. Patrick SL, Kadohiro JK, Waxman SH et al. (1997) IDDM Incidence in a Multiracial Population. The Hawaii IDDM Registry, 1980-1990. Diabetes Care 20: 983-987 